\title{
Evaluating Patterns of Building Envelope Air Leakage with Infrared Thermography
}

\author{
Milad Mahmoodzadeh ${ }^{1}$, Voytek Gretka ${ }^{2}$, Stephen Wong ${ }^{3}$, Thomas Froese ${ }^{1}$ and \\ Phalguni Mukhopadhyaya ${ }^{1, *(D)}$ \\ 1 Department of Civil Engineering, University of Victoria, Victoria, BC V8W 2Y2, Canada; \\ miladmahmoodzadeh@uvic.ca (M.M.); froese@uvic.ca (T.F.) \\ 2 Department of Building Specialty Services, Morrison Hershfield Ltd., Victoria, BC V8W 1C6, Canada; \\ vgretka@morrisonhershfield.com \\ 3 Department of Building Specialty Services, Morrison Hershfield Ltd., Vancouver, BC V5C 6S7, Canada; \\ SWong@morrisonhershfield.com \\ * Correspondence: phalguni@uvic.ca
}

Received: 5 May 2020; Accepted: 25 June 2020; Published: 9 July 2020

Abstract: The next-generation performance-based building energy codes are focusing on minimizing building envelope air leakage. The quantification of air leakage in buildings is typically performed with a blower door test. However, this test does not provide information about the locations of air leakage. The aim of this study is to demonstrate a method involving qualitative and quantitative components that can be used to characterize locations of air leakage with infrared thermography. Since air leakage can have a significant impact on building energy consumption in cold climates, like in Canada, this approach can quickly inform where air barrier discontinuities occurred during construction or where to selectively target air sealing efforts in existing buildings. The observations from this study are presented, based on a thermographic image analysis during a depressurized blower door test at various pressures, in an attempt to quantify the relative rates of air leakage. The results from the investigation showed that infrared thermography (IRT) was able to discern locations and infer relative ratios of air leakage. The qualitative analysis showed that areas of air leakage are more evident under higher pressure difference. The quantitative approach showed that a minimum of $25 \mathrm{~Pa}$ pressure difference was required to detect the air leakage in the vicinity of the window frame, as the surface temperature decreased rapidly (almost $60 \%$ of the indoor surface/outdoor air temperature difference) at this pressure. A temperature index was defined to prioritize the areas of air leakage for retrofitting purposes. Furthermore, a thermal image subtraction method was used to determine the characteristics of the cracks based on thermal patterns. Finally, the practical implication of this study, for building developers, home inspectors, property mangers, and homeowners, is the early detection of air leakage for both existing and newly constructed buildings which could result in energy and cost savings.

Keywords: infrared thermography; air leakage area; quantitative analysis; qualitative analysis; pressure differences

\section{Introduction}

Energy consumption in the built environment has increased considerably over the past decade as a result of population growth, occupants spending more time indoors, indoor air quality, and climate change. According to the International Energy Agency (IEA), buildings and building construction sectors together consume $36 \%$ of the total global energy consumption and are responsible for almost $40 \%$ of direct and indirect greenhouse gas (GHG) emissions [1]. To achieve a low-energy building, a number of early design decisions need to be considered. 
Building re-commissioning and occupant behavioral measures are low-cost and fast-payback pursuits, often considered first. However, re-commissioning should occur on a regular basis, to ensure continuing energy savings, every 3-5 years, or more frequently with occupancy or usage changes [2]. Likewise, fostering sustainable occupant behaviour can be a challenging endeavour and needs to be reinforced continuously due to occupant forgetfulness and turnover [3].

Therefore, physical building components typically need to be addressed such as lighting, domestic hot water, heating, ventilation, and air conditioning (HVAC) systems and the building envelope [4]. Among these methods, air leakage (unintentional air movement through the building envelope) is one of the most influential factors on energy efficiency and thermal comfort [5]. According to previous studies, air leakage is responsible for $10-50 \%$ of building energy demand on an annual basis, largely dependent on age, archetype, and climate [6]. For instance, in cold climates, almost $25 \%$ of the heating load is due to infiltration [7] while a study based in Spain by Meiss and Feijo-Munoz found that air leakage represents $10-27 \%$ of energy demand in the winter [8]. In the US, air leakage is responsible for $13 \%$ and $4 \%$ of heating and cooling loads in office buildings, respectively [9].

Building energy codes and standards are beginning to include air leakage provisions for new construction. For instance, British Columbia's Energy Step Code requires an energy model to demonstrate compliance with energy use intensity (EUI) and thermal energy demand intensity (TEDI) targets, both of which are dependent on the as-tested air leakage rate at occupancy phase [5]. The Passive House Standard requires a maximum air leakage rate of $0.6 \mathrm{ACH}$ (air change per hour) at an induced pressure difference of $50 \mathrm{~Pa}$ [10]. While the National Energy Code for Buildings (NECB) 2011 defined airtightness targets for fenestration and the 2015 edition further introduced targets for the exterior envelope of $0.25 \mathrm{~L} / \mathrm{s} / \mathrm{m}^{2}$ at ambient pressure [11], neither have historically required an air leakage test to demonstrate compliance.

Air leakage is usually measured by the means of the fan pressurization method ("Blower Door Test") described in standards such as ASTM E779, EN 9972:2015 and USACE 2012 [12-14]. The fan pressurization method is based on measuring the total volume of airflow at a pressure difference that is established between the interior and exterior of a building. The ASTM E779 procedure is performed between 10 and $60 \mathrm{~Pa}$ at increments up to $10 \mathrm{~Pa}$. The airflow $\mathrm{Q}$ rate $\left(\mathrm{m}^{3} / \mathrm{h}\right)$ is calculated based on pressure differences $\Delta \mathrm{P}(\mathrm{Pa})$, using the power law as shown in Equation (1). The test is performed under positive and negative pressure to reduce the bias due to wind pressure and/or the stack effect. The result will be the average of the both tests:

$$
\mathrm{Q}=\mathrm{C}(\Delta \mathrm{P})^{\mathrm{n}}
$$

where ' $\mathrm{C}^{\prime}$ ' is the flow coefficient $\left(\mathrm{m}^{3} /\left(\mathrm{h} \mathrm{Pa}^{\mathrm{n}}\right)\right)$ and ' $\mathrm{n}$ ' is the flow exponent that depends on the flow regime (dimensionless) [12]. It should be noted that in an energy modeling program such as EnergyPlus, the rate of infiltration input is defined based on the $\mathrm{L} / \mathrm{s} / \mathrm{m}^{2}$ of an exterior envelope area, which is as per the NECB 2015. Furthermore, as the induced pressure with the blower door test is high and not considered as a typical operating condition, this rate is calculated at an ambient pressure ( $\sim 5 \mathrm{~Pa})$ for energy modeling input which was considered as normal operating conditions.

Although this test is useful for assessing the airtightness of the whole building, it does not give information regarding its location(s) and relative magnitude [10]. In recent years, infrared thermography (IRT) has been investigated as a potential forensic tool for evaluating the thermal performance of building envelopes. This method uses the principles of heat transfer to capture thermal images (thermograms) of surface temperatures. IRT has been used for various research purposes such as comparing and validating simulations of building envelope thermal performance [15]. IRT can also provide immediate spatial information about heat losses due to compromised or poorly installed insulation, moisture accumulation, thermal bridging, and sources of air leakage [16-18]. Areas of potential air leakage can be identified with IRT, as air leakage induces temperature differences at and around the point of air leakage. The magnitude of temperature differences can depend on the size of the leakage point, pressure differences between the inside and outside, and the indoor-outdoor 
temperature difference. These areas can be identifiable with IRT from the inside when the building is depressurized, or from the outside when the building is pressurized [10].

The application of IRT to qualitatively detect air leakage through the building envelope has been the focus of many researchers. For instance, Van De Vijver et.al [19] used IRT with a blower door test to detect sources of air leakage in a building, and studied the impact of pressure differences and temperature differences on the IRT survey. The simulation results showed that higher pressure differences have a negligible benefit for detecting surface temperature differences with IRT after $30 \mathrm{~min}$. However, temperature differences have a more pronounced effect. In another air leakage investigation, Kalamees [9] performed blower door and IRT tests simultaneously on houses in Estonia and showed that the main sources for air leakage were ceiling/floor-wall interfaces, window-wall interfaces and the interface of interior walls with exterior walls and roofs. In a different study, Colantonio and Desroches [18] studied how pressurization- and depressurization-induced air leakage created unique thermal patterns on walls in different types of masonry-clad buildings. Fabrizio Ascione et al. [20] performed an energy audit with thermography on a historical building in Italy, and showed that improving airtightness was one of the most effective energy upgrades while preserving its historical appearance.

A few recent studies have attempted a quantitative application of IRT in this field with some success. The most recent studies in Mediterranean climates showed that a test window has considerably more air leakage than the roller shutter handle, and that the cold area around the leakage locations grows gradually with increasing pressure; however, temperature differences did not have significant influence on the qualitative approach [7,10], contrary to findings by Van De Vijver et al. [19]. Interestingly, the study found that pressure differences up to $25 \mathrm{~Pa}$ were responsible for $60 \%$ of the changes in surface temperature and had a much smaller effect thereafter. Liu et al. [21] simulated air leakage through cracks using a combination of heat transfer and fluid dynamics principles, validated with simulations using IRT on a pressurized test chamber and in an office building (in-situ). Their results demonstrated that crack size could be predicted within a relative error of $20 \%$, while predicting the air infiltration rate had a relative error of only $3 \%$ in situ.

Pressurization by means of a fan offers a much more uniform pressure distribution than can be achieved by natural pressure differences (climate-dependent stack effect, wind, and building mechanical systems), and is therefore recommended for IRT. Hart [22] concluded that pressure differences between the interior and exterior should be at least $10 \mathrm{~Pa}$, and the temperature differences should be constant for the most accurate results (minimum $\Delta \mathrm{T}=5^{\circ} \mathrm{C}$ ). Wahlgren and Sikander [23] similarly concluded a minimum $\Delta \mathrm{T}$ of $5{ }^{\circ} \mathrm{C}$, ideally $10^{\circ} \mathrm{C}$. However, the guidelines do not agree on the recommended temperature and pressure differences for a reliable evaluation of air leakage using IRT [24] as outlined in Table 1.

Table 1. Recommended temperature and pressure differences for detection of air leakage with infrared thermography (IRT).

\begin{tabular}{ccc}
\hline Standard & $\begin{array}{c}\text { Recommended Minimum } \boldsymbol{\Delta \text { T for }} \\
\text { Detection of Air Leakage }\end{array}$ & $\begin{array}{c}\text { Recommended Pressure } \\
\text { Difference }(\boldsymbol{\Delta P})\end{array}$ \\
\hline RESNET [25] & $1.7^{\circ} \mathrm{C}$ & $10 \mathrm{~Pa}$ \\
\hline ASTM E1186-03 [26] & $5{ }^{\circ} \mathrm{C}$ & $10-50 \mathrm{~Pa}$ \\
\hline NMS 022713 [27] & $20{ }^{\circ} \mathrm{C}$ & $5-10 \mathrm{~Pa}$ \\
\cline { 2 - 3 } & $10^{\circ} \mathrm{C}$ & $10-25 \mathrm{~Pa}$ \\
\hline ASTM C 1060-11a [28]; & None $\left(10^{\circ} \mathrm{C}\right.$ minimum for IRT) & $5 \mathrm{~Pa}$ (IRT from low-pressure side) \\
\hline
\end{tabular}

Aforementioned published literatures indicate that the majority of the researchers focused on the qualitative approach with IRT to determine sources of air leakage, and only a few recent studies in a cooling-dominated Mediterranean climate attempted a quantitative analysis. An absence 
of quantitative investigations with IRT in colder climates like Canada, where air leakage plays a significant role in thermal energy demand intensity forms part of the motivation for this experimental study. Furthermore, prioritizing areas of air leakage for sealing purposes have not been studied yet, whereas this study has attempted to address this issue by developing different quantitative approaches. Finally, the proposed study aims to uncover a new horizon in the thermal assessment of building envelopes where quantitatively distinguishing areas of air leakage from thermal bridges is often challenging.

\section{Objective}

The objective of this study is to assess the potential of infrared thermography (IRT) as a tool for both qualitative localization and the relative quantitative comparison of air leakage. Thermal patterns created by air leakage are evaluated at different pressure differences, in an attempt to correlate surface temperatures with relative magnitudes of crack sizes and positions.

\section{Methodology}

\subsection{Test Object}

The experimental study was performed in a room of a laboratory building constructed in 1948 and is located in Victoria, BC, Canada. The room has a floor area of $95 \mathrm{~m}^{2}$ and a ceiling height of approximately $2.5 \mathrm{~m}$, including two exterior walls, one interior wall and one interior corridor wall with two doors. During the measurement period, the room was heated by the HVAC system, controlled at $20{ }^{\circ} \mathrm{C}$ by a thermostat. Fenestration was single glazed in original wood frames, with aluminum frame retrofit inserts (hybrid frames). The largest window facing southeast was selected to assess the air leakage, containing both fixed and operable components as shown in Figure 1a. Thermal images captured the interface between the glazing and aluminum frame, aluminum frame and wood frame, and the wood frame and drywall as shown in Figure $1 \mathrm{~b}$. The camera was positioned at a distance of $1 \mathrm{~m}$ from the window as shown in Figure 1c. It should be noted that to avoid any reflection from the photographer, the angle of tilt is 5 degrees from the photographer to the targeted objects.

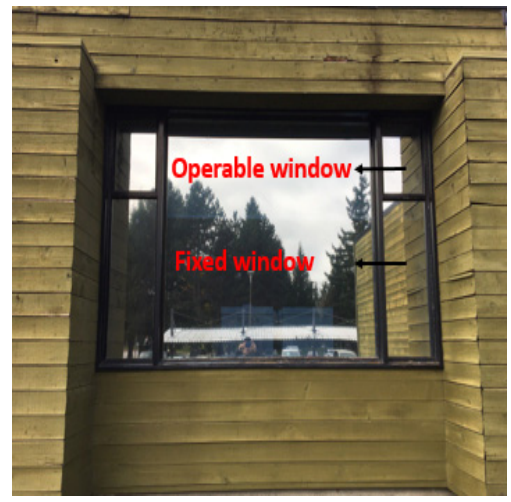

(a)

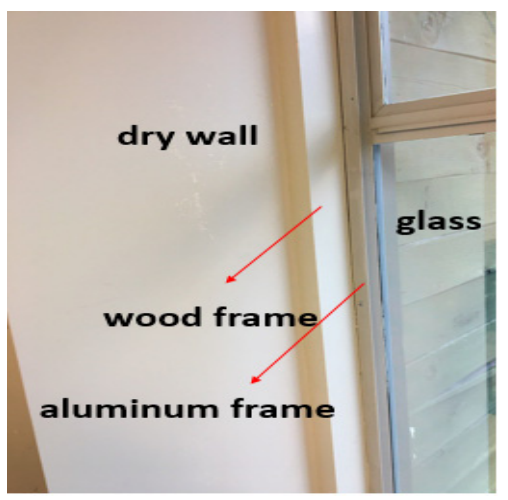

(b)

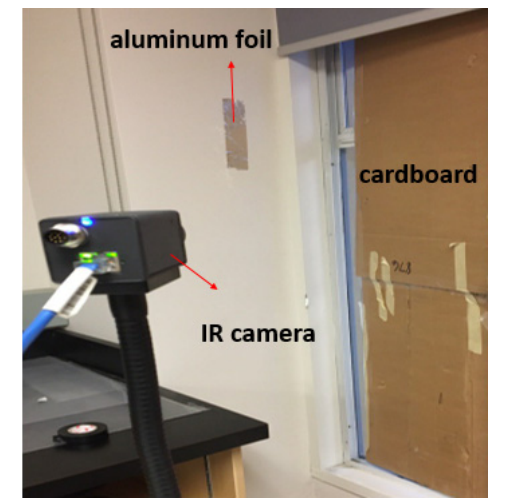

(c)

Figure 1. Test area viewed from (a) the exterior; (b) the interior, showing the window frames; and (c) the camera position.

\subsection{Equipment}

Measurement equipment included an infrared (IR) camera, temperature sensors (thermocouples), a wind speed measurement tool (anemometer), and a blower door test apparatus. Before the measurements were carried out, all the equipment was calibrated according to the manufacturers' specifications. During the IR camera calibration, the reflected temperature was measured and the emissivity values of the materials were defined before the tests. Specifications of the equipment and the IR camera are described in Tables 2 and 3. Inside and outdoor air temperatures were recorded 
by means of a 4 -channel data logger, with an accuracy of $\pm 1 \%$. The blower door used was capable of achieving a maximum flow of $12,631 \mathrm{~m}^{3} / \mathrm{h}$ at a 50 Pa pressure difference and minimum flow of $12.5 \mathrm{~m}^{3} / \mathrm{h}$ at $10 \mathrm{~Pa}$ pressure difference. The gauge pressure accuracy is $\pm 0.25 \mathrm{~Pa}$ or $\pm 5 \%$, which ever is greater.

Table 2. Technical specification of the equipment.

\begin{tabular}{cccc}
\hline Sensor & Measurement Range & Uncertainties & Resolution \\
\hline Thermocouple Type k & $-200{ }^{\circ} \mathrm{C}$ to $1250{ }^{\circ} \mathrm{C}$ & $\pm 2 .{ }^{\circ} \mathrm{C}$ or $\pm 0.75 \%$ & $0.01{ }^{\circ} \mathrm{C}$ \\
\hline Data logger & $-200{ }^{\circ} \mathrm{C}$ to $1372{ }^{\circ} \mathrm{C}$ & $\pm 1 \%$ & $0.1{ }^{\circ} \mathrm{C}<1000,1{ }^{\circ} \mathrm{C}>1000$ \\
\hline Hot wire anemometer & $20 \mathrm{~mm} / \mathrm{sec}$ to $40 \mathrm{~m} / \mathrm{sec}$ & $\pm 3 \%$ & $0.01 \mathrm{~m} / \mathrm{s}$ \\
\hline
\end{tabular}

Table 3. Specification of the IR camera (FLIR A65).

\begin{tabular}{cc}
\hline Measuring Range & $-25^{\circ} \mathrm{C}$ to $100{ }^{\circ} \mathrm{C}$ \\
\hline Accuracy & $\pm 5{ }^{\circ} \mathrm{C}\left( \pm 9{ }^{\circ} \mathrm{F}\right)$ or $5 \%$ of reading \\
\hline Observation display range & $0.05{ }^{\circ} \mathrm{C}$ at $30^{\circ} \mathrm{C}$ \\
\hline Wavelength range & $7.5-13 \mu \mathrm{m}$ \\
\hline IR resolution & $640 \times 512$ \\
\hline Field of view & $45^{\circ} \times 37^{\circ}$ \\
\hline Instantaneous field of view (IFOV) & 1.31 mrad \\
\hline Detector & Uncooled VOx microblometer
\end{tabular}

\subsection{Test Procedure}

Fan-pressurized tests were performed to quantify the air leakage characteristics of the room. Furthermore, to detect the areas of air leakage with IRT, thermal images were taken simultaneously while the room was depressurized with the fan. To validate the methodology, the tests were performed on different days with varying exterior conditions outlined in Table 4. For all the days studied, indoor temperatures were higher than outdoor temperatures because the tests were performed during the heating months. The initial temperature difference was around $10^{\circ} \mathrm{C}$ on each day. The first three tests were performed in the evening after sunset or in the early morning to avoid the impact of solar radiation on surface temperature. Moreover, since the building surfaces radiate energy to the sky, the tests were performed on both overcast (Days 1 to 3) and clear sky (Days 4 and 5) days to evaluate the variability of thee results. To reduce the effect of transmitted exterior radiation onto the measurement surface, cardboard was placed over the window as shown in Figure 1c.

Table 4. Climatic conditions at the beginning of each test.

\begin{tabular}{|c|c|c|c|c|c|c|}
\hline & & Day 1 & Day 2 & Day 3 & Day 4 & Day 5 \\
\hline \multirow{5}{*}{ Outdoor } & Temperature $\left({ }^{\circ} \mathrm{C}\right)$ & 9 & 8 & 7 & 12 & 6 \\
\hline & Humidity (\%) & 85 & 90 & 93 & 75 & 80 \\
\hline & Wind speed $(\mathrm{m} / \mathrm{s})$ & 1.6 & 1.2 & 2 & 2.5 & 1 \\
\hline & Sky condition & Cloudy & Cloudy & Cloudy & $\begin{array}{l}\text { Sunny day and } \\
\text { clear sky }\end{array}$ & $\begin{array}{l}\text { Sunny day and } \\
\text { clear night sky }\end{array}$ \\
\hline & Time of test & $\begin{array}{l}\text { before sunrise; } \\
\text { 5:00 a.m. }\end{array}$ & $\begin{array}{l}\text { after sunset } \\
\text { 8:00 p.m. }\end{array}$ & $\begin{array}{l}\text { before sunrise } \\
\text { 5:00 a.m. }\end{array}$ & $\begin{array}{l}\text { after sunrise } \\
\text { 10:00 a.m. }\end{array}$ & $\begin{array}{l}\text { after sunset } \\
\text { 8:30 p.m. }\end{array}$ \\
\hline \multirow{2}{*}{ Inside } & Temperature $\left({ }^{\circ} \mathrm{C}\right)$ & 20 & 19.6 & 19.6 & 19.8 & 20 \\
\hline & Humidity (\%) & 45 & 45 & 47 & 48 & 50 \\
\hline
\end{tabular}

For each test, thermal images were taken at $0 \mathrm{~Pa}$, followed by 15 to $65 \mathrm{~Pa}$ in increments of $10 \mathrm{~Pa}$, for a total of six pressure differences (e.g., 15, 25, 35, 45, 55, $65 \mathrm{~Pa}$ ). It should be noted that due to the 
poor airtightness of the room, the blower door test was not able to generate pressure difference lower than $15 \mathrm{~Pa}$. Measurements were performed and recorded continuously over a period of $5 \mathrm{~min}$ at each pressure level (for a total of $\sim 30 \mathrm{~min}$ ), with a data acquisition interval of $1 \mathrm{~s}$ by the IR camera. Therefore, each test involved a sequential video with 300 thermograms where the result of the last thermogram at each pressure difference was used for the analysis with FLIR ResearchIR software. All data loggers were configured to collect measurements from the temperature sensors with the same data acquisition interval as the IR camera $(1 \mathrm{~s})$. The wind speed measurement device (anemometer) was located adjacent to the window to measure the outdoor air speed, recorded by data loggers. The pressure difference is defined by the user and controlled by the blower door apparatus software. The system includes a manometer that measures the pressure difference across the fan. The pressure sensor, associated with the blower door, was in a location was carefully selected to prevent any influence of airflow from the fan.

In order to calibrate the IR camera, the emissivity of a material and reflected ambient temperature should be determined. The reflected ambient temperature was determined by using crumpled aluminum foil stretched onto a surface in the field of view of an IR camera. The reflected temperature is the average temperature of the foil if the emissivity is set to 1 in the IR camera [31]. For emissivity, black electrical tape with known emissivity (0.95) was attached to the target at least two hours before the measurements to achieve thermal equilibrium. The emissivity of the target was then determined by adjusting the emissivity of the images until the target temperature was equivalent to the temperature of the tape [32]. Hence, the emissivity of the painted drywall, wood frame, and aluminum frame were found to be $0.95,0.90$ and 0.83 , respectively. Finally, the surface temperatures of the targets were calculated by correcting for reflective temperature and the surface emissivity values.

\section{Results and Discussion}

\subsection{Air Leakage Evaluation}

Results showed that the measured airflow at a pressure differential of 50 Pa was $4013.0 \mathrm{~m}^{3} / \mathrm{h}$ (16.9 air changes per hour (ACH)). Applying Equation (1), it results a flow exponent (n) of 0.517 and a flow coefficient of $0.147 \mathrm{~m}^{3} / \mathrm{s} / \mathrm{Pa}^{0.517}$. For context, air leakage was considerably higher $\left(\sim 0.6 \mathrm{~L} / \mathrm{s} / \mathrm{m}^{2}\right.$ at ambient pressure " $5 \mathrm{~Pa}$ ") than the requirement in Part 8 of the NECB 2015 [11] where a building envelope airtightness target of $0.25 \mathrm{~L} / \mathrm{s} / \mathrm{m}^{2}$ of the exterior envelope area is suggested as a model input at ambient conditions ( $5 \mathrm{~Pa}$ ). It is to be noted that some leakage may be occurring from the adjacent conditioned space. The results indicate that the room is relatively poorly air-sealed and requires further investigation to identify all sources of air leakage. A combined blower door test with IRT was applied to evaluate the areas of air leakage both qualitatively and quantitatively, as discussed in the following sections.

\subsection{Qualitative Observations of Infrared Thermography}

Figure 2 shows the thermal images taken to the window frame (WF) during the tests carried out on Day 1. This day was selected as representative because similar qualitative results were obtained on Day 2 and Day 3. However, the results on Day 3 and Day 4 showed that external conditions such as solar and night sky radiation had a major impact on thermal imagery. For instance, during the sunny day (Day 4), the effect of $\Delta \mathrm{P}$ variations on the surface temperature were marginal as a result of direct solar radiation on the window. The test on Day 5 showed, due to night sky radiation, the window frame surface temperatures dropped to below that of the outdoor air at higher $\Delta \mathrm{P}$. 


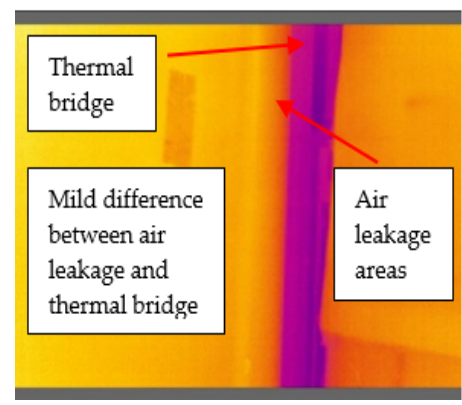

(a) $0 \mathrm{~Pa}$

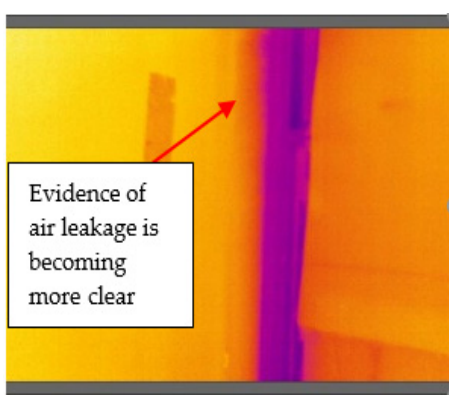

(b) $15 \mathrm{~Pa}$

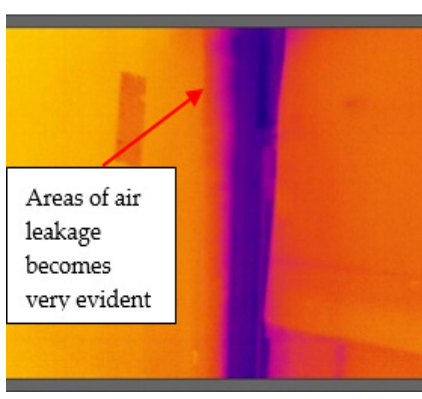

(c) $25 \mathrm{~Pa}$

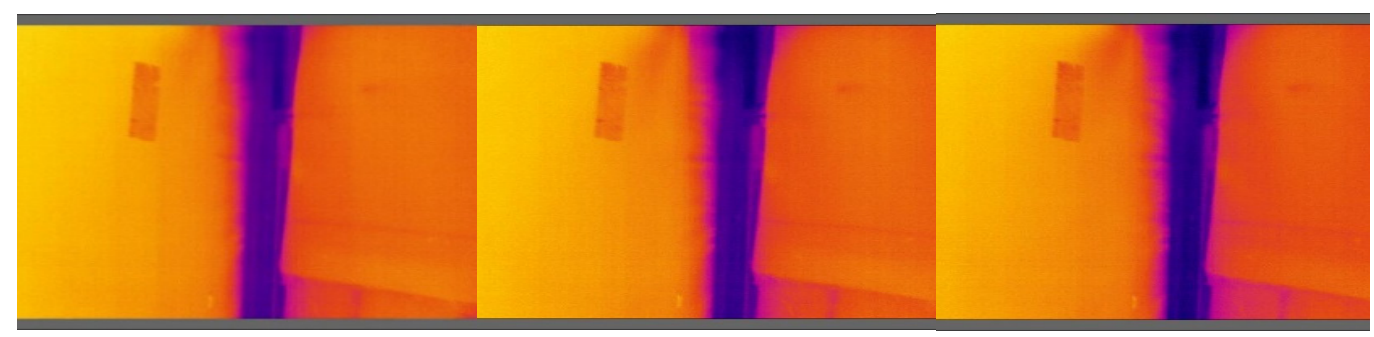

(d) $35 \mathrm{~Pa}$

(e) $45 \mathrm{~Pa}$

(f) $55 \mathrm{~Pa}$

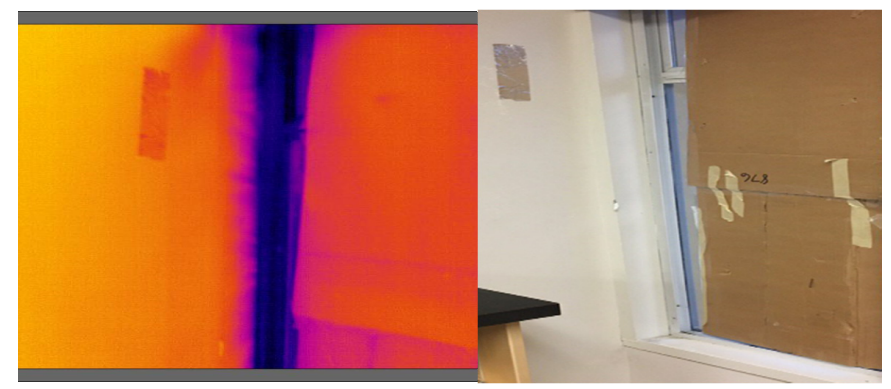

(g) $65 \mathrm{~Pa}$

(h) Visual image

Figure 2. Window frame thermal images (temperature difference in degrees Celsius) taken from the interior in a depressurized room, at varying $\triangle \mathrm{P}$ : (a) $0 \mathrm{~Pa}$; (b) $15 \mathrm{~Pa}$; (c) $25 \mathrm{~Pa}$; (d) $35 \mathrm{~Pa}$; (e) $45 \mathrm{~Pa}$; (f) $55 \mathrm{~Pa}$; (g) $65 \mathrm{~Pa}$; (h) Visual image.

In Figure 2, the warmer appearing vertical areas are cardboard which was used to shield the IR camera from the outdoor radiation. Colder appearing areas are the window glazing and the aluminum frame, which closely resemble the temperature of outdoor air as a result of higher thermal conductivity. Without higher pressures, it is challenging to: (1) determine the presence of air leakage, and (2) identify the source/location of air leakage. However, air leakage becomes more evident with increasing pressure difference $(\Delta P)$ as previously suggested by Hart [21]. When analyzing the following thermal images at $25 \mathrm{~Pa}$ or less, one can potentially interpret these images as only thermal bridges of the higher conductive window frames, since the color differences around the frames still appear solid (no streaks/lines) and thus, one may not be able to definitively detect any signs of air leakage pathways under a 25 Pa pressure differential. However, at higher magnitudes of enclosure pressurization/depressurization $((\Delta \mathrm{P}$ greater than $25 \mathrm{~Pa}$ ), it starts to become more visually apparent where the streaks of air leakage patterns are actually located. Based on these images, it appears that pressure differential magnitudes of about $25 \mathrm{~Pa}$ and above can more effectively illustrate where the air leakage pathways are located [10]. Therefore, the minimum $\Delta \mathrm{P}$ of 5 and $10 \mathrm{~Pa}$ proposed by other standards [27-30] and Hart [22], respectively, were not appropriate to obtain meaningful results in this particular case.

\subsection{Quantitative Results of Infrared Thermography}

Figure 3 is a visual representation of where the data was selected for further analysis. Three regions of interest with the same dimensions (Boxes 1-3) were defined for the wood frame. Two other regions 
of interest were defined for the aluminum foil (Box 4; reflected temperature) and the aluminum frame (Box 5). The exterior air temperature held approximately constant during each test. However, since the depressurization test constantly introduced outdoor air with lower temperature and heating supply air was masked off, the inside air temperature decreased by $\sim 1.7^{\circ} \mathrm{C}$ during the course of the $25 \mathrm{~min}$ test. It is to be noted that the indoor air temperature varies during the test, and in this study all the calculations are based on temperature differences.

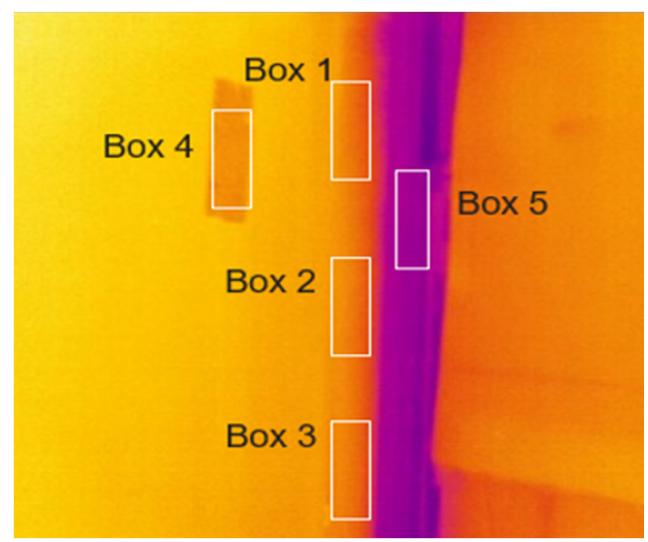

Figure 3. Regions of interest: Box 1-3: wood frame; Box 4: aluminum foil; Box 5: aluminum frame.

Figure 4 shows that by increasing $\Delta \mathrm{P}$, the mean temperature of boxes 1 to 3 decreased due to the higher air flow and velocity of the colder outdoor air to indoors through the corresponding adjacent cracks. Therefore, it can be concluded that a more convective heat transfer occurs as a result of increased $\Delta \mathrm{P}$. This effect was more significant within box 1 , indicating a larger crack in the vicinity of this box compared to others. It is also seen that the decrease in temperature at $\Delta \mathrm{P}<25 \mathrm{~Pa}$ appeared to be insignificant, likewise, as shown in the qualitative approach. However, it is notable that surface temperatures decreased significantly at $\Delta \mathrm{P}$ of $25 \mathrm{~Pa}$ which were approximately 3,2 , and $1{ }^{\circ} \mathrm{C}$ for boxes 1 to 3 , respectively. The effect of a higher $\Delta \mathrm{P}$ is less important as the surface temperature in each of the boxes approaches that of the outdoor air. The surface temperature of box 1 at the end of the test approached the exterior air temperature, while Boxes 2 and 3 had differences of about $1.5-2.5^{\circ} \mathrm{C}$ compared to the exterior.

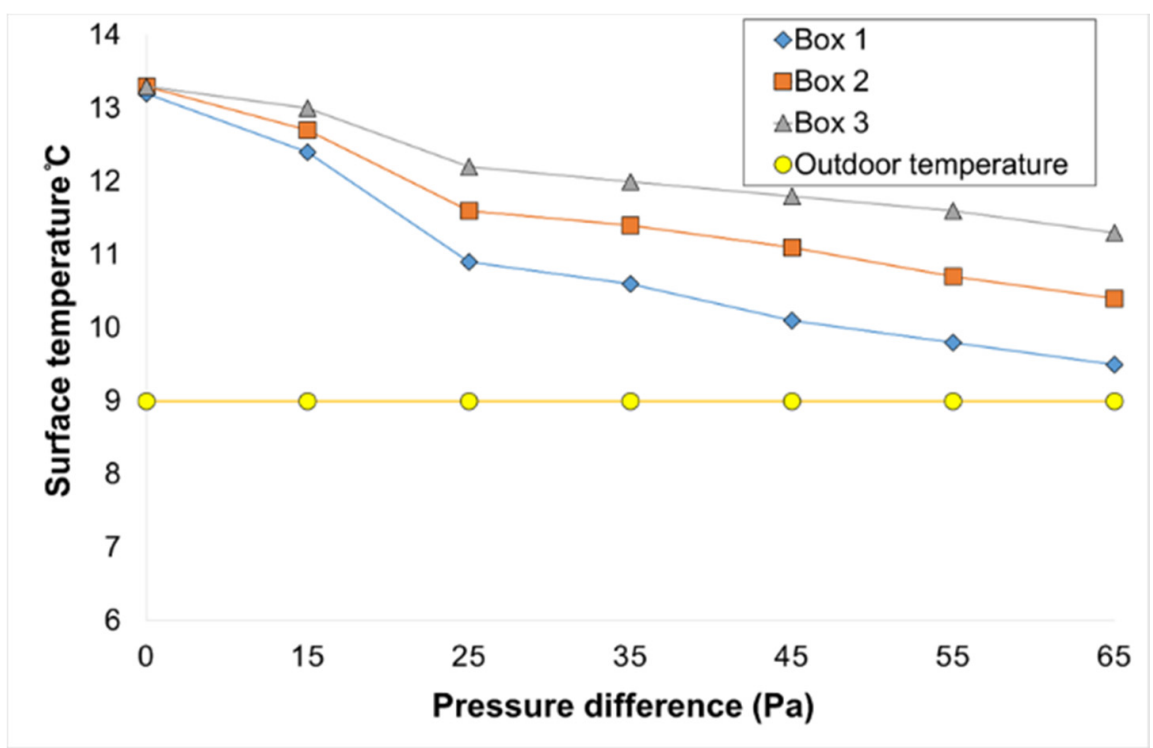

Figure 4. Variation of the surface temperature at the different pressures (Day 1). 
Furthermore, an alternative approach, a dimensionless temperature index (TI), was implemented to identify and prioritize the areas of air leakage. This index is often used for the hygrothermal performance assessment of the exterior building envelopes in any climate [33]. The index is defined as in Equation (2):

$$
T I=\frac{T_{s, i n}-T_{o}}{T_{i}-T_{o}}
$$

where $T_{s, i n}$ is the indoor surface temperature, $T_{o}$ is the outdoor temperature and $T_{i}$ is the indoor temperature. The temperature index (TI) has a value between 0 and 1 , where 0 represents an equal exterior air and interior surface temperatures, while 1 represents equal interior surface and interior temperature. From Equation (2) it can be deduced that a higher TI represents a lower air leakage rate at the vicinity of the air leakage areas.

Equation (2) is based on the assumption that the building envelope is in a steady-state condition. Therefore, a test on Day 3 was performed where the pressure was maintained at $\Delta \mathrm{P}=60 \mathrm{~Pa}$ for at least $30 \mathrm{~min}$ and thermal images were recorded. As shown in Figure 5, the surface temperature of three areas (Boxes) decreased significantly in the first $15 \mathrm{~min}$ because of the high rate of convective heat transfer, while after around $20 \mathrm{~min}$ the decrease in temperature between measurements was negligible due to the reduced convective heat transfer.

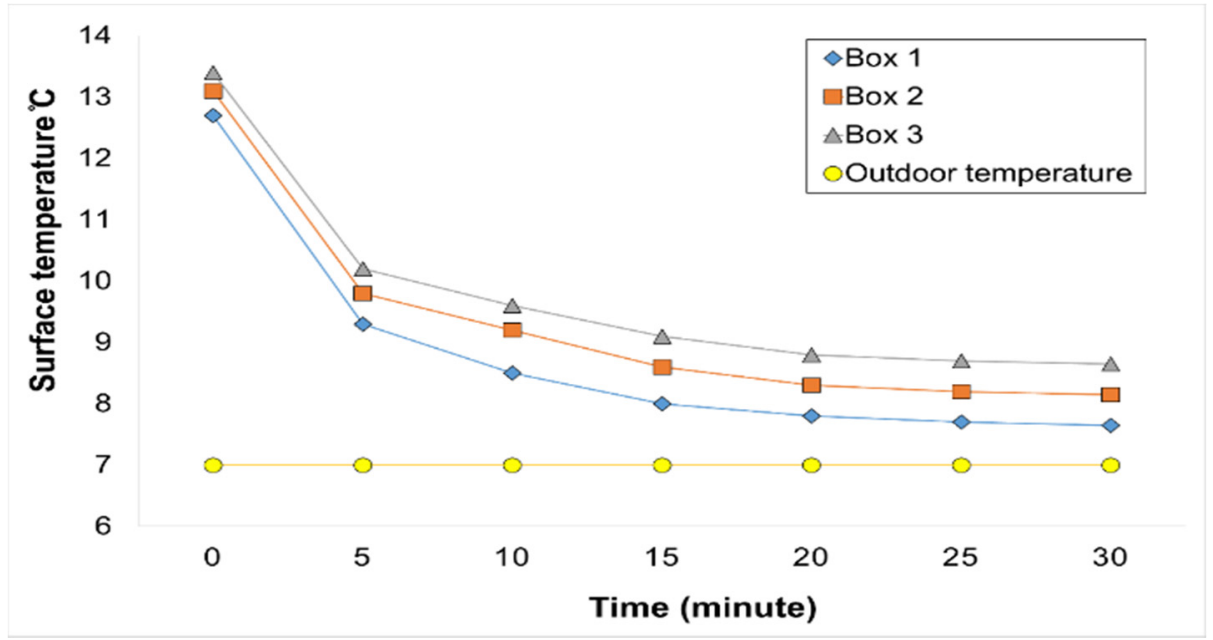

Figure 5. Variation of the surface temperature over time at $60 \mathrm{~Pa}$ (Day 3).

In order to determine the air leakage contribution of an area, temperature indices (TIs) were calculated for the three selected regions of interest (Boxes) as shown in Table 5 . At $30 \mathrm{~min}$, the TIs for Boxes 1 to 3 were $0.06,0.10$ and 0.14 , respectively. However, before the depressurization test $(t=0)$ these values were $0.45,0.48$ and 0.51 for boxes 1 to 3 , respectively, implying that the contribution of air leakage to the surface temperature of Box 1 was more than that of Boxes 2 or 3 . As mentioned above, the variation of indoor air temperature from $19.60{ }^{\circ} \mathrm{C}$ to $18.60{ }^{\circ} \mathrm{C}$ was considered in the calculations of TIs (Table 5). It should be noted that considering the constant indoor air temperature after $30 \mathrm{~min}$ would vary TIs between $6 \%$ and $16 \%$.

Table 5. Variation of the temperature index (TI) over the time $(\Delta \mathrm{P}=60 \mathrm{~Pa})$.

\begin{tabular}{|c|c|c|c|c|c|c|c|c|}
\hline \multirow{2}{*}{$\begin{array}{c}\text { Time } \\
\text { (minutes) }\end{array}$} & \multicolumn{3}{|c|}{ Surface Temperature $\left({ }^{\circ} \mathrm{C}\right)$} & \multicolumn{3}{|c|}{ Temperature Index (TI) } & \multirow{2}{*}{$\begin{array}{c}\text { Outdoor } \\
\text { Temperature }\left({ }^{\circ} \mathrm{C}\right)\end{array}$} & \multirow{2}{*}{$\begin{array}{c}\text { Indoor } \\
\text { Temperature }\left({ }^{\circ} \mathrm{C}\right)\end{array}$} \\
\hline & Box 1 & Box 2 & Box 3 & Box 1 & Box 2 & Box 3 & & \\
\hline 0 & 12.72 & 13.12 & 13.41 & 0.45 & 0.48 & 0.51 & 7 & 19.60 \\
\hline 30 & 7.65 & 8.15 & 8.65 & 0.06 & 0.10 & 0.14 & 7 & 18.60 \\
\hline
\end{tabular}


It is also seen that after depressurization, TI was reduced by a factor of 7.5, 4.8, and 3.6 for Boxes 1, 2 and 3, respectively. This analysis suggests that the TI ratio can be a quantitative indicator of relative air leakage in this scenario. Hence, this approach could be helpful on a whole building scale, where areas of air leakage identified in this manner should likely be prioritized compared to other sources for air sealing.

Figure 6 illustrates an image subtraction approach in an effort to study air leakage thermal pattern delineation at a different $\Delta \mathrm{P}$. The subtracted thermogram $\left(\Delta \mathrm{T}_{\Delta \mathrm{P}}\right)$ depicts the difference between the initial thermogram (i.e., at $\Delta \mathrm{P}=0$ ) and the thermogram at different pressure differential levels (i.e., $\Delta \mathrm{P}=15,25,35,45,55$ and $65 \mathrm{~Pa}$ ) as shown in Figure 6. The motivation for this approach originated from analyzing Figure 2 at a higher $\Delta \mathrm{P}(55 \mathrm{~Pa}$ or $65 \mathrm{~Pa})$ or lower $\Delta \mathrm{P}(15 \mathrm{~Pa}$ or $25 \mathrm{~Pa})$ where the thermal patterns appear to be similar and show poor air leakage delineation (i.e., the locations of air leakage were unclear).

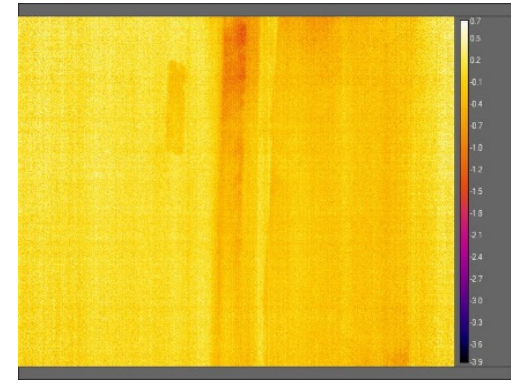

(a)

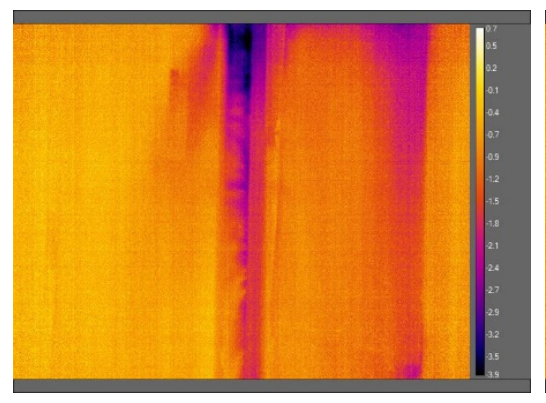

(d)

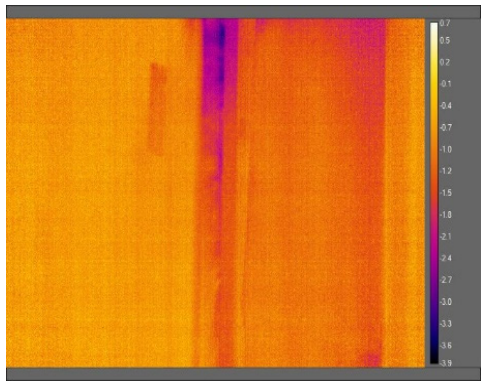

(b)

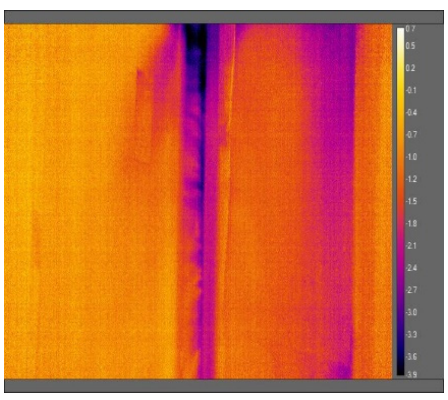

(e)

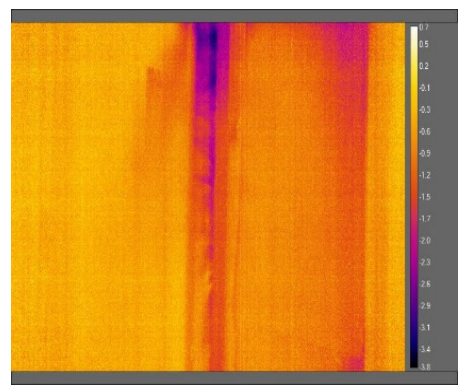

(c)

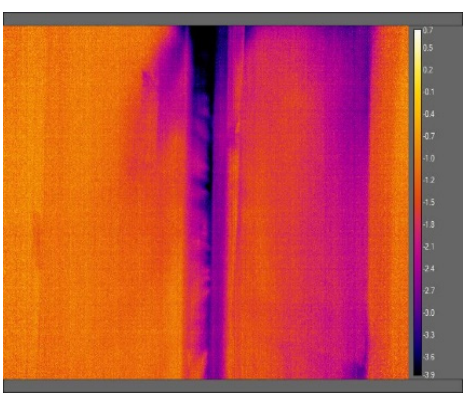

(f)

Figure 6. Subtracted thermograms $(\mathbf{a})(\Delta P=15)-(\Delta P=0) ;(\mathbf{b})(\Delta P=25)-(\Delta P=0) ;(\mathbf{c})(\Delta P=35)-$ $(\Delta P=0) ;(\mathbf{d})(\Delta P=45)-(\Delta P=0) ;(\mathbf{e})(\Delta P=55)-(\Delta P=0) ;(\mathbf{f})(\Delta P=65)-(\Delta P=0)$

Higher $\Delta \mathrm{T}_{\Delta \mathrm{P}}$ shows an increased directional resolution of thermal patterns (see Figure 6) at sources of air leakage. Another advantage of this method is that the characteristics of air leakage through cracks are potentially better identified by thermal patterns and temperature differences, such as the direction of air infiltration (crack geometry), or the relative rate of infiltration. Finally, image subtraction could be helpful in the detection of small cracks where surface temperature variation is within the temperature detection error of the infrared camera. For example, in Figure 2 at lower pressure differences (15-25 Pa), small cracks were not visible, while in Figure 6 these differences are considerably more pronounced.

Based on the thermal patterns in Figure 6 (along the probable path of air flow), a subsequent analysis was conducted on the data by selecting three lines of interest as outlined in Figure $7 \mathrm{a}$. Figure $7 \mathrm{~b}-\mathrm{d}$ shows the temperature difference variation through the lines at three different $\Delta \mathrm{T}_{\Delta \mathrm{P}}$. The power trend line $\left(y=a x^{b}\right)$ fit coefficients and goodness of fit are shown in Table 6 for the range of $\Delta \mathrm{T}_{\Delta \mathrm{P}}$ studied for each line of interest. 
Table 6. Statistical parameters: Lines 1-3 $\left(y=a x^{b}\right)$.

\begin{tabular}{|c|c|c|c|c|c|c|c|c|c|}
\hline \multirow{2}{*}{$\begin{array}{l}\text { Subtracted Pressure } \\
\text { Differential }(\Delta(\Delta P))\end{array}$} & \multicolumn{3}{|c|}{$a^{*}$} & \multicolumn{3}{|c|}{$b^{* *}$} & \multicolumn{3}{|c|}{$R^{2}$} \\
\hline & Line 1 & Line 2 & Line 3 & Line 1 & Line 2 & Line 3 & Line 1 & Line 2 & Line 3 \\
\hline 15-0 Pa & 1.33 & 0.56 & 0.15 & -0.13 & -0.04 & 0.22 & 0.20 & 0.01 & 0.09 \\
\hline 25-0 Pa & 3.19 & 2.02 & 1.57 & -0.11 & -0.09 & -0.13 & 0.54 & 0.35 & 0.38 \\
\hline 35-0 Pa & 3.69 & 2.58 & 1.82 & -0.13 & -0.15 & -0.24 & 0.59 & 0.53 & 0.47 \\
\hline 45-0 Pa & 4.36 & 3.04 & 2.77 & -0.09 & -0.13 & -0.32 & 0.56 & 0.42 & 0.76 \\
\hline 55-0 Pa & 4.60 & 3.91 & 3.21 & -0.08 & -0.11 & -0.24 & 0.60 & 0.61 & 0.79 \\
\hline 65-0 Pa & 4.99 & 4.73 & 3.92 & -0.07 & -0.10 & -0.23 & 0.64 & 0.63 & 0.82 \\
\hline
\end{tabular}

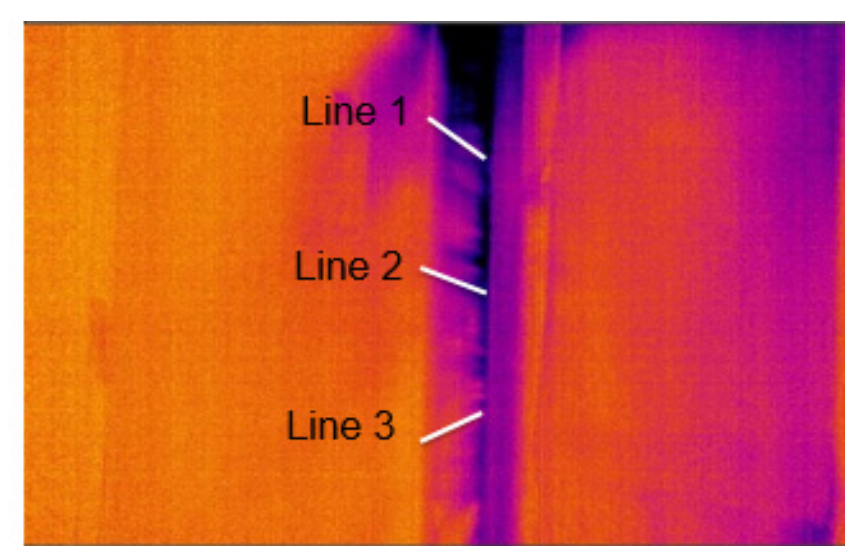

(a)

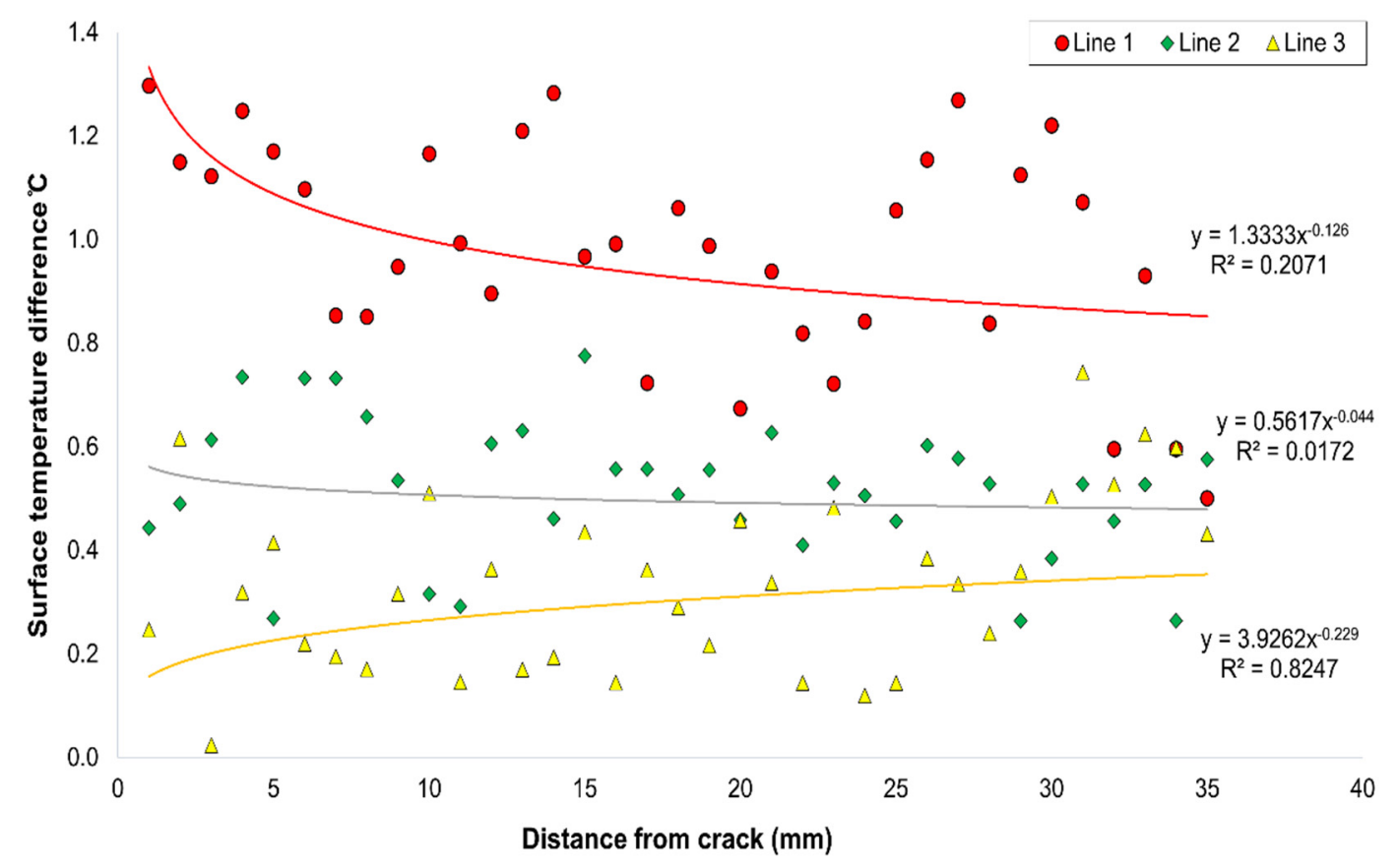

(b) (15-0 Pa)

Figure 7. Cont. 


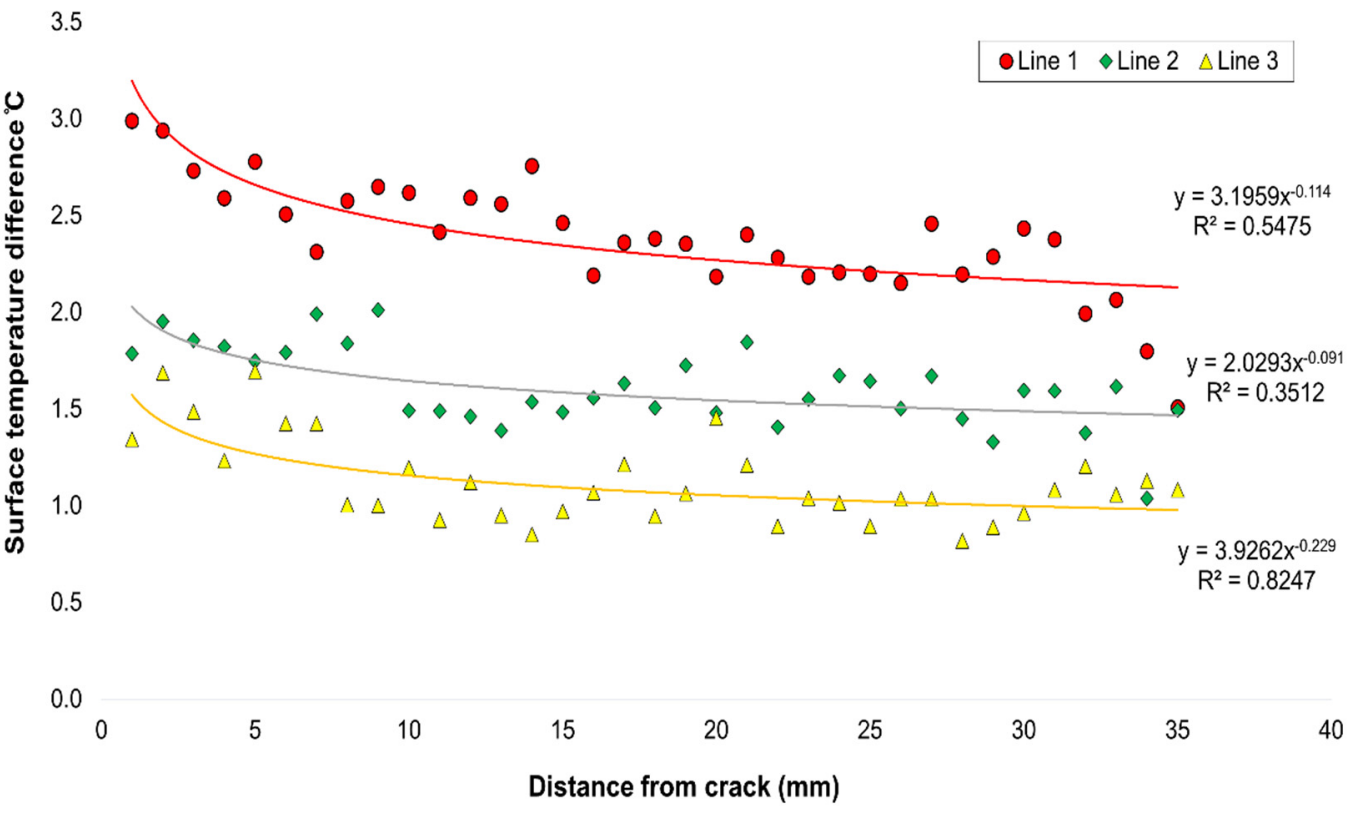

(c) $(25-0 \mathrm{~Pa})$

6.0

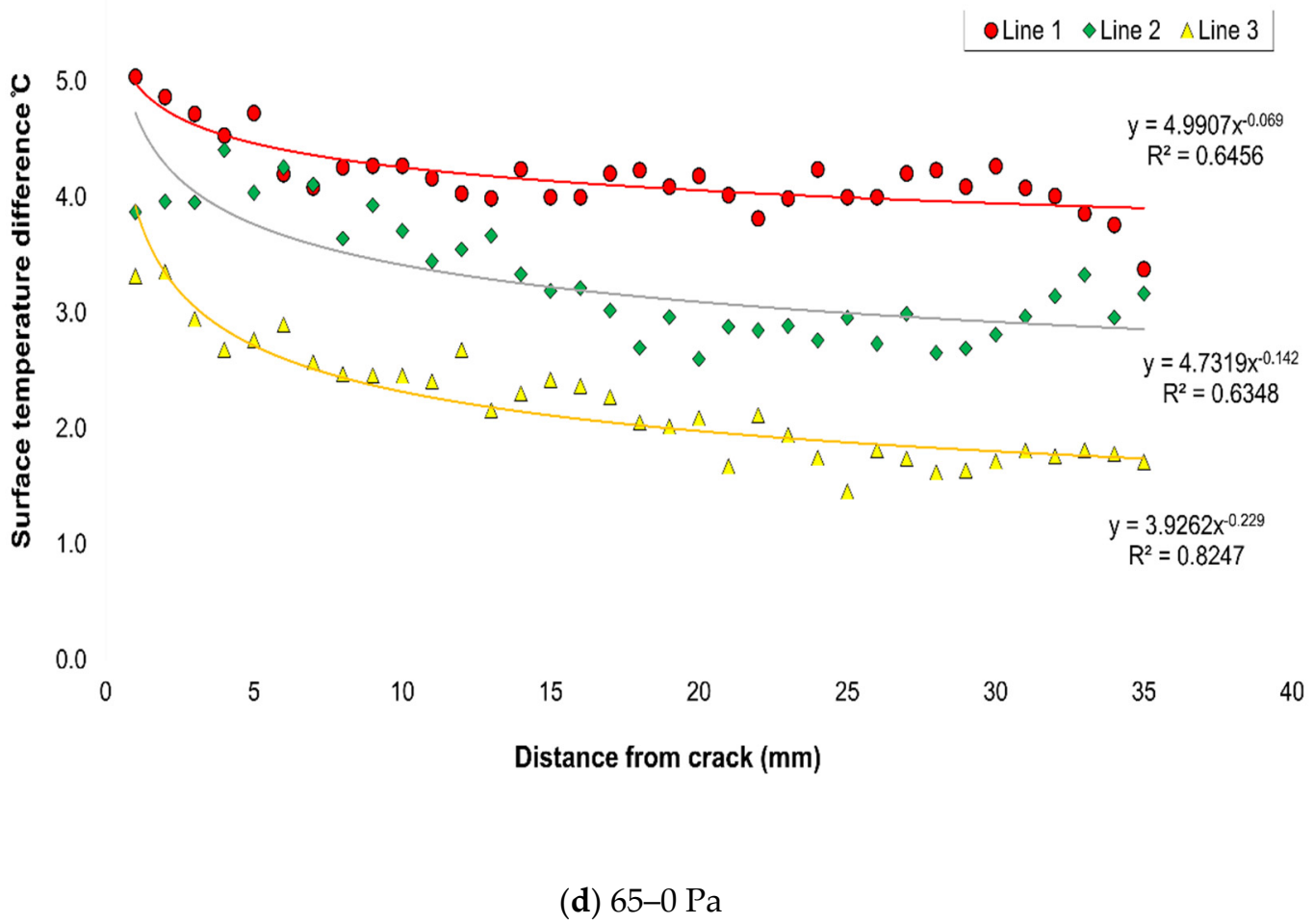

Figure 7. (a) Paths of air leakage analyzed, and the surface temperature differences vs. the distance from the crack at: (b) 15-0 Pa, (c) 25-0 Pa, and (d) 65-0 Pa.

Interestingly, the intercept coefficient $a$ (i.e., the temperature difference adjacent to crack) appears to be largest for line 1 and smallest for line 3 in each scenario, indicating a larger temperature difference and consequent heat loss at the crack. The surface temperature close to the crack is influenced more at a higher pressure differential along line 1 than along lines 2 and 3, likely indicating a corresponding difference in the air leakage rate. This is justifiable based on thermal patterns in Figure 6. The intensity 
of flow streamlines around line 1 is larger compared to other lines, which suggests a higher rate of airflow around it.

When comparing the lines studied, the coefficient $b$ does not exhibit a meaningful trend until the subtracted pressure differential $(\Delta(\Delta \mathrm{P}))$ is $45 \mathrm{~Pa}$, where it increases in magnitude $\left(\left|\mathrm{b}_{\text {Line1 }}\right|<\left|\mathrm{b}_{\text {Line2 }}\right|<\left|\mathrm{b}_{\text {Line3 }}\right|\right)$; this threshold $\Delta(\Delta \mathrm{P})$ is possibly as a result of higher induced pressures required for accurately characterizing relative air leakage contribution on surface temperatures around different cracks. In terms of the $b$ coefficient, it is conceivable that smaller cracks have less air infiltration and consequently induce less heat transfer, therefore surface temperature effects are smaller at higher distances from the crack. Furthermore, it is noted that the goodness of fit $\left(R^{2}\right)$ increases with each increasing $\Delta(\Delta \mathrm{P})$ for all the lines.

\section{Conclusions}

The result of the blower door test showed that the air leakage rate for the test object (laboratory room) was considerably higher in the test than suggested by the building codes. Combining the blower door test with thermography identified that certain regions at the window frame to wall interface were considerable sources of air leakage, and should be prioritized for air sealing. It was also demonstrated that the information obtained from the infrared thermography can be used for both qualitative and quantitative analyses for the comparison of air leakage characteristics.

From a qualitative perspective, the surface temperature near the aluminum and wood frame interface appeared colder than in other areas, and the increasing $\Delta \mathrm{P}$ resulted in even lower temperatures. Areas of air leakage were slightly detectable at a lower $\Delta \mathrm{P}$; however, they could be easily missed due to the surrounding thermal bridging of building assemblies. Higher $\Delta \mathrm{P}$ was more effective at delineating the air leakage from thermal bridges or other potential thermal anomalies. Notably, in this study, thermograms at $25 \mathrm{~Pa}$ were required for the reasonable detection of air leakage with thermography, contrary to some published standards citing 5-10 Pa.

From a quantitative perspective, IRT showed that most of the surface temperature decrease $(\sim 60 \%$ of $\Delta \mathrm{T})$ occurred between 0 and $25 \mathrm{~Pa}$. Increasing $\Delta \mathrm{P}$ above $25 \mathrm{~Pa}$ appeared to have a smaller impact on the surface temperature since the surface approached the outdoor air temperature, likely due to the effect of higher convection heat transfer. It should be noted that the contribution of a lower temperature difference vs. a higher flow rate to overall heat transfer needs further study. For further evaluation, two approaches of quantitative prioritization of air leakage were adopted: (1) the assessment of the average temperature index in three pre-defined regions of interest, and (2) an assessment of the surface temperature profile along a path of air infiltration at different $\Delta \mathrm{P}$ using the image subtraction technique. These approaches showed promise in inferring the location of air leakage and the relative size of cracks based on streamline intensities, which were not evident in previous studies. It is desirable to keep room temperature constant to enhance the accuracy of quantitative approaches as well as delineate the sources of air leakage from thermal bridging effects in buildings. Reducing the duration of the test would presumably achieve this outcome, not allowing enough time for room temperature to decrease appreciably. Future modifications to this methodology could explore how to apply a correction technique to the results as an additional normalization exercise.

The qualitative and quantitative approaches used in this study could potentially be implemented by practitioners for the identification and prioritization of sources of air leakage in buildings. Furthermore, as a blower door test becomes a building code requirement in an increasing number of Canadian jurisdictions, performing IRT simultaneously is a potentially valuable complement to characterizing/prioritizing sources of air leakage.

To absolutely quantify the air leakage contribution of each component, additional information, such as the flow exponent " $n$ " and flow coefficient " $\mathrm{C}$ ", are required independently for each building component deficiency (cracks or gaps). The crack geometry and the air velocity can then be obtained based on the image subtraction and TI approach. This will form part of future investigations. 
It should be noted that the tests were performed during the heating months, where high temperature differences between the interior and exterior were achievable. Future work will test the feasibility of the performing IRT at lower temperature differences as a sensitivity analysis exercise. A pressurized condition will also be evaluated to confirm the feasibility of obtaining meaningful results from exterior thermography. Moreover, during the next phase of this research initiative, larger areas of building will be investigated to differentiate areas of air leakage from thermal bridges, for a more complete evaluation of where and how much air leakage is occurring through a building envelope.

Author Contributions: Conceptualization, M.M., V.G. and P.M.; formal analysis, M.M., V.G. and P.M.; investigation, M.M.; methodology, M.M. and V.G.; project administration, P.M.; validation, M.M. and V.G.; writing-original draft preparation, M.M., P.M. and V.G.; writing—review and editing, M.M., V.G., P.M., S.W. and T.F. All authors have read and agreed to the published version of the manuscript.

Funding: This research project received no external funding.

Acknowledgments: Authors acknowledge the support of Morrison Hershfield Ltd. for this project. The authors would like to thank the support staffs of building science laboratory at the University of Victoria for providing an experimental set-up in the E-hut building for this project, and Matt Seymour for assistance with data evaluation.

Conflicts of Interest: The authors declare no conflict of interest.

\section{References}

1. International Energy Agency. Available online: https://www.iea.org/topics/energyefficiency/buildings/ (accessed on 28 April 2020).

2. ASHRAE. ASHRAE Guideline 0-2019, The Commissioning Process; American Society of Heating, Refrigerating and Air-Conditioning Engineers: Atlanta, GA, USA, 2019.

3. McKenzie-Mohr, D. Fostering Sustainable Behavior: An Introduction to Community-Based Social Marketing, 3rd ed.; New Society Publishers: Gabriola Island, BC, Canada, 2011.

4. Cho, K.H.; Kim, S.S. Energy Performance Assessment According to Data Acquisition Levels of Existing Buildings. Energies 2019, 12, 1149. [CrossRef]

5. RDH Building Science Inc. Illustrated Guide: Achieving Airtight Buildings; BC Housing, BC Hydro, and the City of Vancouver: Burnaby, BC, Canada, 2017.

6. Pinto, M.; Viegas, J.; de Freitas, V. Air permeability measurements of dwellings and building components in Portugal. Build. Environ. 2011, 46, 2480-2489. [CrossRef]

7. Lerma, C.; Barreira, E.; Almeida, R.M. A discussion concerning active infrared thermography in the evaluation of buildings air infiltration. Energy Build. 2018, 168, 56-66. [CrossRef]

8. Meiss, A.; Feijó-Muñoz, J. The energy impact of infiltration: A study on buildings located in north central Spain. Energy Effic. 2015, 8, 51-64. [CrossRef]

9. Kalamees, T. Air tightness and air leakages of new lightweight single-family detached houses in Estonia. Build. Environ. 2007, 42, 2369-2377. [CrossRef]

10. Barreira, E.; Almeida, R.M.; Moreira, M. An infrared thermography passive approach to assess the effect of leakage points in buildings. Energy Build. 2017, 140, 224-235. [CrossRef]

11. National Research Council (NRC). National Energy Code of Canada for Buildings; National Research Council Canada: Ottawa, ON, Canada, 2015.

12. ASTM International (American Society for Testing and Materials). E779-19; Standard Test Method for Determining Air Leakage Rate by Fan Pressurization; ASTM: West Conshohocken, PA, USA, 2019.

13. International Organization for Standardization (ISO). EN ISO 9972: 2015-Determination of Air Permeability of Buildings-Fan Pressurization Method; ISO: Geneva, Switzerland, 2015.

14. US Army Corps of Engineers (USACE). Air Leakage Test Protocol for Building Envelopes_Version 3; US Army Corps of Engineers: Champaign, IL, USA, 2012.

15. Emanuela, G.; Sanjuan, C.; Blanco, E.; Heras, M.R. Experimental assessment and modelling of the performance of an open joint ventilated façade during actual operating conditions in Mediterranean climate. Energy Build. 2012, 54, 363-375.

16. Balaras, C.A.; Argiriou, A. Infrared thermography for building diagnostics. Energy Build. 2002, 34, 171-183. [CrossRef] 
17. Asdrubali, F.; Baldinelli, G.; Bianchi, F. A quantitative methodology to evaluate thermal bridges in buildings. Appl. Energy 2012, 97, 365-373. [CrossRef]

18. Gonçalves, M.D.; Gendron, P.; Colantonio, A. Commissioning of Exterior Building Envelopes of Large Buildings for Air Leakage and Resultant Moisture Accumulation Using Infrared Thermography and Other Diagnostic Tools; Thermal Solutions: Sarasota, FL, USA, 2007.

19. Van De Vijver, S.; Steeman, M.; Carbonez, K.; Van Den Bossche, N. On the Use of Infrared Thermography to Assess Air Infiltration in Building Envelopes, International Workshop: Quality of Methods for Measuring Ventilation and Air Infiltration in Buildings, Proceedings; Air Infiltration and Ventilation Centre (AIVC): Brussels, Belgium, 2014.

20. Ascione, F.; Bianco, N.; De Masi, R.F.; de'Rossi, F.; Vanoli, G.P. Energy retrofit of an educational building in the ancient center of Benevento. Feasibility study of energy savings and respect of the historical value. Energy Build. 2015, 95, 172-183. [CrossRef]

21. Liu, W.; Zhao, X.; Chen, Q. A novel method for measuring air infiltration rate in buildings. Energy Build. 2018, 168, 309-318. [CrossRef]

22. Hart, J. A Practical Guide to Infrared Thermography for Building Surveys; Building Research Establishment: Watford, UK, 1991.

23. Wahlgren, P.; Sikander, E. In Methods and materials for an airtight building. In Proceedings of the 11th International Conference on Thermal Performance of the Exterior Envelopes of Whole Buildings, Buildings XI, Clearwater Beach, FL, USA, 5-9 December 2010.

24. Dufour, M.B.; Derome, D.; Zmeureanu, R. Analysis of thermograms for the estimation of dimensions of cracks in building envelope. Infrared Phys. Technol. 2009, 52, 70-78. [CrossRef]

25. Residential Energy Services Network (RESNET). RESENET Interim Guidelines for Thermographic Inspections of Buildings; Residential Energy Services Network: Oceanside, CA, USA, 2012.

26. ASTM International (American Society for Testing and Materials). E1186-17; Standard Practices for Air Leakage Site Detection in Building Envelopes and Air Barrier Systems; ASTM: West Conshohocken, PA, USA, 2017.

27. National Master Specification (NMS). NMS 022713 Thermographic Assessment- Building Envelope; National Research Council Canada: Ottawa, ON, Canada, 2007.

28. ASTM International (American Society for Testing and Materials). C1060-11a; Standard Practice for Thermographic Inspection of Insulation Installations in Envelope Cavities of Frame Buildings; ASTM: West Conshohocken, PA, USA, 2015.

29. International Organization for Standardization (ISO). ISO 6781-3: 2015, Performance of Buildings-Detection of Heat, Air and Moisture Irregularities in Buildings by Infrared Methods_Part 3: Qualifications of Equipment Operators, Data Analysts and Report Writers; ISO: Geneva, Switzerland, 2015.

30. British Standards Institution (BSI). BS EN 13187:1999, Thermal Performance of Buildings-Qualitative Detection of Thermal Irregularities in Building Envelops-Infrared Method, Brussels; BSI: London, UK, 1999.

31. ASTM International (American Society for Testing and Materials). E1933-14; Standard Practice for Measuring and Compensating for Emissivity Using Infrared Imaging Radiometers; ASTM: West Conshohocken, PA, USA, 2014.

32. ASTM International (American Society for Testing and Materials). E1862-14; Standard Practice for Measuring and Compensating for Reflected Temperature Using Infrared Imaging Radiometers; ASTM: West Conshohocken, PA, USA, 2014.

33. Mill, P.A.D. Thermographic Diagnosis of Building Envelope Deficiencies, Fathers of Confederation Center; Report Series No. 28; Public Works Canada: Ottawa, ON, Canada, 1979; ISBN 0-662-50335-X.

(C) 2020 by the authors. Licensee MDPI, Basel, Switzerland. This article is an open access article distributed under the terms and conditions of the Creative Commons Attribution (CC BY) license (http://creativecommons.org/licenses/by/4.0/). 